\title{
LOGIC OUGHTN'T BE NORMATIVE
}

\author{
Christopher J. Searle
}

UDK 16(049.2)

Original scientific paper

https://doi.org/10.32701/dp.22.1.1

Presumably, the exponent of logical normativity believes it to be the case that rational agents ought to reason logically. If the converse holds, and the exponent of logical normativity believes either (a) that it is false that rational agents ought to reason logically or (b) that the claim that rational agents ought to reason logically is not truth-functional, then any attempt to formulate sound arguments in support of their position will be either question-begging or self-contradictory. To argue in favour of the normative status of logic involves the assumption that the issue is substantive. I draw a distinction between deontic and axiological normativity as applied to logical theory and demonstrate that because deontic sentences are not truth-functional, logic cannot be normative in the deontic sense. I conclude that the only sense in which logical theory may be thought of as normative is axiologically.

Presumably, the exponent of logical normativity believes it to be the case that rational agents ought to reason logically.

The claim that logic is normative is itself declarative - it is either true, or it is false. However, the corollary of this claim is that rational agents ought to reason logically, which is an injunction in the imperative mood - it is nonextensional. Putting aside the question of whether such a move can legitimately escape Hume's Guillotine, the proponent of logical normativity surely believes it to be true that rational agents ought to reason logically. If the converse holds, and the exponent of logical normativity believes either (a) that it is false that rational agents ought to reason logically or (b) that the claim that rational agents ought to reason logically is not truth-functional, then any attempt to formulate sound arguments in support of their position will be either question-begging or self-contradictory. To argue in favour of the normative status of logic involves the assumption that the issue is substantive. ${ }^{1}$

* Christopher J. Searle, University of Oxford, E-mail: christopher.searle@conted.ox.ac.uk

1 It assumed from the outset that the only reasonable sense in which logic can be held to be normative is categorically, as opposed to hypothetically. The hypothetical imperative: 'if we want to reason well, then we ought to reason within the bounds of logic' is unin- 
In dealing with the question of the normative status of logical theory, much emphasis has been given over to the explication of logic, validity, and of inference, but very little to precisely what might be meant by normativity (Tappolet 2014, 39-54). It is within this gap in the literature that this paper hopefully finds a place.

The arguments presented here aim to demonstrate how the general claim that logical theory is normative arises from a failure to recognise two distinct notions relating to Jörgensen's Dilemma. The first is that sentences in the imperative mood are not truth-functional, and so it cannot be true that successful reasoners ought to follow the rules of logic; the second, following Tappolet, is that a distinction can be drawn between deontic and axiological normativity as applied to logical theory (Tappolet 2013). The bulk of the paper is devoted to demonstrating that because deontic sentences are not truth-functional, logic cannot be normative in the deontic sense; and it concludes that the only sense in which logical theory may be thought of as normative is axiologically.

Jörgensen's Dilemma can be summarised as follows:

1. Arguments containing imperatives are either valid or invalid.

2. If such arguments are valid, then either:

a. An account of validity is required that is not reliant on truth functionality, or

b. An account of the truth functionality of imperatives is required.

3. If such arguments are invalid, then ethical reasoning involving imperatives is mistaken.

(Jörgensen 1937, 288-296)

The standard definition of validity assumed throughout, is that a valid argument is one such that there is no possible world where the premises are true and the conclusion false (Talbot 2017). In this paper I attempt to grasp the second horn of the dilemma (3) and defend the notion that since deontic sentences are not truth functional, arguments with deontic premises are invalid in this sense of the term. ${ }^{2}$

formative. Reasoning well means something like reasoning within the bounds of logic. So, the material conditional: 'If we want to reason well, then we ought to reason within the bounds of logic' is translatable mutatis mutandis to: 'If we want to reason within the bounds of logic, then we ought to reason within the bounds of logic'. The exponent of logical normativity presumably intends more by their claim than: if we want $p$, then we ought $p$, which may be better described by a theory of desire.

2 I propose an expressivist account of ethical inference in another paper (see (Searle 2019)), where I defend the notion that ethical statements are indexical non-propositional attitudes, and this accounts for both embedded and unembedded conative content without equivocation, including in deontic modal sentences. 
The thesis I wish to defend concords loosely with Harman's challenge, which suggests that a dichotomy pertains between theories of deductive logic and theories of reasoning, where the former are concerned with logical relations and the latter with rules of belief revision. The general claim that logic is normative results from a conflation of the two (Harman 2002, 171-186). As appealing as this solution is, there are some compelling arguments for rejecting it (John MacFarlane 2004). So, rather than focusing on the distinction between logic and reasoning, the distinction drawn here is between types of normativity.

What is not disputed is that logical theory sets standards for reasoning well, or that theory informs practice etc. Logic is clearly instrumentally valuable to the reasoner; if truth is the end of reasoning, logic is surely the means (Reinmuth and Siegwart 2016, 417-432).

The proponent of logical normativity might view the main argument as suggesting that since there are no normative facts, to claim it is a fact that logic is normative, is false. But this would be to set up a strawman. It is conceded that logic could be normative, and if it is, then it need not necessarily be a normative fact that logic is normative. But if there are normative facts, then what sort of fact would fit the claim that logic is normative?

The question of the normative status of logic in not trivial, it has significant ethical consequences. If logic is normative, and deontic sentences are taken to be truth-functional, that is to say, if there are normative facts, then ethical realism becomes a far more tenable position (Labukt 2019)

Perhaps the most quoted passage attesting to the normative status of logic is from Frege's The Basic Laws of Arithmetic:

'Laws of logic ... are the most general laws, which prescribe universally the way in which one ought to think if one is to think at all' (Frege and Furth 1964). ${ }^{3}$

However, as Gillian Russell proposes, the claim that logic is normative is equivocal. She argues that there are three distinct reasons for supposing that logic is 'normative'. The first is that the logic has normative consequences,

3 This particular passage seems to inform the bulk of the literature. However, some confusion may have arisen from a potential mistranslation. “...dass sie die allgemeinsten sind, die überall da vorschreiben, wie gedacht werden soll, wo überhaupt gedacht wird” (Frege 1962). The German for ought, 'sollen', does not actually occur in the original. The verb that is used is 'vorschreiben' meaning to prescribe. I would therefore like to proffer the following less contentious translation: "The laws of thought...are the most general, which universally prescribe how to think, where there is thought at all." The key thing to take away from Frege's suggested showing, is just that this putative deontic sentence is actually an indicative conditional, not an injunction. The passage expresses the hypothetical imperative 'If you think at all, then you will think by the laws of thought' as opposed to the categorical deontic imperative 'one ought to think by the laws of thought', which may lend support to the notion that Frege would have thought of logic as being axiologically normative, but not deontically so. 
the second is that logical laws are often violated whereas descriptive laws are not, the third is that if logic is normative it can be demarcated from other similar academic disciplines and saved from accusations of constructivism (Russell 2020, 371-388).

The reason that logic is perceived as normative in contrast to its sister disciplines of mathematics and physics, is that the subject matter of the latter two determines the truth or falsity of their respective constituent propositions. Maths and physics are descriptive, not normative. The correct description of a physical phenomenon will give rise to a true theory of physics, whereas it is unclear what sort of phenomena, if any, logic attempts to describe. Logic seemingly has no subject matter; it is not about anything, as Wittgenstein prosaically put it:

"The logic of the world is prior to all truth and falsehood" (Wittgenstein and others 1988).

If truth functionality is a necessary condition for a sentence to be included within the scope of logic, then deontic sentences clearly fall outside of the scope of logic. However, as Vranas argues, there are good reasons for wanting to include deontic sentences within the scope of logic, namely that in normal discourse we do seem to reason with imperatives (Vranas 2008, 529-572). It is for precisely this reason that many philosophers choose to grasp the first horn of Jörgensen's dilemma and argue for an extended account of validity. Others, such as Wolenski, have opted for the alternative of retaining a classical conception of validity but instead stressing that deontic sentences are truth functional, but the burden of proof is significant (Woleński 2018).

It is assumed that logical theory sets norms of reasoning by which arguments are judged to be good or bad, but that such norms are insufficient for deontic normativity (Talbot 2015, 4).

My master argument for the non-normativity of logic runs as follows:

1. If logic is deontically normative, then we ought to think logically.

2. It is not the case that we ought to think logically.

3. Therefore, it is not the case that logic is deontically normative.

In support of (2), we can confidently assert that if deontic sentences are not truth bearing, then it is not literally true that we ought to think logically. This leads to the following expanded argument:

1. If logic is deontically normative, then we ought to think logically.

2. If deontic sentences are not truth bearing, then it is not the case that we ought to think logically.

3. Deontic sentences are not truth bearing.

4. It is not the case that we ought to think logically.

5. Therefore, it is not the case that logic is deontically normative. 
Assuming, ceteris paribus, that the sentential variable $\mathrm{O}$ is extensional, then the expanded argument is valid in the propositional calculus, as the following semi-formalisation demonstrates:

1. $\mathrm{N} \supset \mathrm{O}$

2. $\sim \mathrm{D} \supset \sim \mathrm{O}$

3. $\sim \mathrm{D}$

Assumption.

4. $\sim \mathrm{O}$

2 \& 3 Modus Ponens

5. $/ \therefore \sim \mathrm{N}$

$4 \& 1$ Modus Tollens

Where:

$\mathrm{N}$ : Logic is deontically normative.

O: We ought to think logically.

D: Deontic sentences are not truth bearing

Unless there is good reason to believe that imperatives are truth functional, and (3) is false, then $\mathrm{O}$ cannot be true, so the argument is sound, QED.

The proponent of normativity may attempt to rebut this argument by claiming that it begs the question, or that it fails its own test. It might seem that if we accept premise (3) that deontic sentences are not truth bearing then, as per Jörgensen (Jörgensen 1937, 288-296), we cannot claim that O (the apodosis of the conditional statement (1)) is either true of false, and consequently we cannot determine if the argument is valid or invalid.

However, in negating the apodosis $\mathrm{O}$ of the conditional statement (1), we are not making a deontic claim. The deontic variable is bound by the negation. Following SDL (McNamara 2019), the statement 'it is not the case that we ought to think logically' is not logically equivalent to 'we ought not to think logically'.

$$
\sim(\mathrm{OBp}) \not \mathrm{OB} \sim \mathrm{p}
$$

The statement 'it is not the case that we ought to think logically' is simply the negation of the claim that 'we ought to think logically'.

$\sim(\mathrm{OBp})$ asserts that the term 'OBp' fails to signify.

Thus, although both protasis and apodosis are false, the material conditional premise (1) remains true in $£_{1}$.

1. If logic is deontically normative, then we ought to think logically.

It is not the case that logic is deontically normative and it is not the case that we ought to think logically.

Peter Schaber is one of many philosophers who have argued for the existence of normative facts (Schaber and Nitta 2005, 107-122). The master argument presented here stands or falls with the success of his claim. If there are normative facts, then premise (3) is false and the argument is unsound. 
It is not the case that we ought to think logically, because the sentence 'we ought to think logically' is imperative not declarative, and therefore not truth bearing. Thus, the extended argument does not commit the fallacy of petitio principii; it remains valid.

There may be axiologically normative facts but there cannot be deontically normative facts as Woleński argues. Deontic modal verbs are only definable intracategorically (Searle 2019). As Frege suggested, imperatives have a sense but no reference (Steinberger 2017, 143-162). The deontic modal operators do not signify. For instance, in SDL the deontic modal OBp does not express a proposition, it does not quantify $p$; it does not assert that some state of affairs $p$ pertains. OB is only definable in terms of other deontic modals, such as permissibility, PE. 'Permissible that $p$ ' means something like 'not obligatory that not $p$ ', whereas 'obligatory that $p$ ' means something like 'not permissible that not $p$ ' etc. It seems like 'ought' means something like 'obliged', 'obliged' means something like 'should', 'should' means something like 'ought', etc. It remains entirely unclear how such imperatives, the definitions of which are clearly narrowly circular, can be used to construct deontically normative facts, where facts stand in contradistinction to theories and to values (Rundle 1993).

What counts as a normative concept is generally uncontroversial, and similarly uncontroversial is the division of normative concepts into those that are evaluative and those that are deontic (Tappolet 2014, 39-54). The distinction is exclusive and exhaustive. If normative concepts are not deontic, then they are axiological. Therefore, if logic is normative, it is only axiologically so.

By this distinction, the following claim is definable as deontically normative: 'You ought not to believe a sentence is true when it is not.' (Russell 2020, 371-388) We can, of course, posit a counterfactual material conditional that seems to encapsulate the same meaning but is at the same time free of deontic modals: 'if you believe a sentence is true when it is not, then you will be in error.' By our criterion, such a sentence can be described as axiologcally normative, but not as deontically normative. We can say of logic that it is normative in an axiological sense if we are psychologically disposed to value consistency.

The distinction between axiological normativity and deontic normativity, reflects the distinction between hypothetical and categorical imperatives. Contrast 'you ought to quit smoking' with 'if you don't want to develop lung cancer, then you ought to quit smoking'. The former is a deontic sentence, a categorical imperative, that it not truth functional. The latter is a hypothetical imperative and can be translated salva vertiate to the contrapositive material conditional: 'If you quit smoking, then you won't develop lung cancer', which is non-normative. 
In conclusion then, unless a conclusive bridge principle is forthcoming, it seems as if there is no escape from Hume's guillotine, and so the master argument I have presented above is sound. Since deontic sentences are not truth bearing, it is not the case that logic is deontically normative. As Gillian Russell so eloquently put it: "Assuming you can't get an 'ought' from an 'is', it will follow that logic isn't normative.” (Russell 2020, 371-388)

\section{Bibliography}

Frege, Gottlob. 1962. Grundgesetze Der Arithmetik. 2. unveränderte Aufl. ed. Hildesheim: Olms.

Frege, Gottlob and Montgomery Furth. 1964. The Basic Laws of Arithmetic : Exposition of the System. Berkeley: University of California Press.

Harman, Gilbert. 2002. Internal Critique: A Logic is Not a Theory of Reasoning and a Theory of Reasoning is Not a Logic, edited by Dov M. Gabbay, Ralph H. Johnson, Hans Jürgen Ohlbach and John Woods. Vol. 1 Elsevier.

John MacFarlane. "In what Sense (if any) is Logic Normative for Thought?"

Jörgensen, Jörgen. 1937. “Imperatives and Logic.” Erkenntnis 7 (1): 288-296.

Labukt, Ivar Russøy. 2019. "Is Logic Distinctively Normative?"

McNamara, Paul. "Deontic Logic.” The Stanford Encyclopedia of Philosophy. Metaphysics Research Lab, Stanford University, accessed Jul 15, 2020, https://plato. stanford.edu/archives/sum2019/entries/logic-deontic/.

Reinmuth, Friedrich and Geo Siegwart. 2016. "Inferential Acts and Inferential Rules. the Intrinsic Normativity of Logic.” Analyse \& Kritik 38 (2): 417-432.

Rundle, Bede. 1993. Facts. London: Duckworth.

Russell, Gillian. 2020. “Logic Isn’t Normative.” Inquiry 63 (3-4): 371-388.

Schaber, Peter and T. Nitta. 2005. "Normative Facts.” In Studies into the Foundations of an Integral Theory of Practice and Cognition, 107-122. Sapporo: Hokkaido University Press.

Searle, Christopher, John. "The Frege-Geach Problem and Token-Reflexive Non-Propositional Attitudes.” Oxford University: Conted.

Steinberger, Florian. 2017. "Frege and Carnap on the Normativity of Logic." Synthese 194 (1): 143-162.

Talbot, Marianne. “Critical Reasoning.” Philosophy Now., last modified /02/19, accessed Jul 14, 2020

- 2017. Critical Reasoning : A Romp through the Foothills of Logic for the Complete Beginner. Seattle, Washington: CreateSpace Independent Publishing Platform.

Tappolet, Christine. 2013. "Evaluative Vs. Deontic Concepts.” In International Encyclopedia of Ethics: American Cancer Society.

— 2014. "The Normativity of Evaluative Concepts." In Mind, Values, and Metaphysics. Philosophical Essays in Honor of Kevin Mulligan, Volume 2, edited by Anne Reboul, 39-54. 
Vranas, Peter B. M. 2008. "New Foundations for Imperative Logic I: Logical Connectives, Consistency, and Quantifiers *.” Noûs 42 (4): 529-572.

Wittgenstein, Ludwig, David Pears, Brian McGuinness, and Bertrand Russell. 1988. Tractatus Logico-Philosophicus. Pbk. ed. London: Routledge.

Woleński, J. 2018. "Deontic Sentences, Possible Worlds and Norms.” Revus 34 (34).

Apstract

\section{LOGIC OUGHTN'T BE NORMATIVE}

\section{CHRISTOPHER J. SEARLE}

Presumably, the exponent of logical normativity believes it to be the case that rational agents ought to reason logically. If the converse holds, and the exponent of logical normativity believes either (a) that it is false that rational agents ought to reason logically or (b) that the claim that rational agents ought to reason logically is not truth-functional, then any attempt to formulate sound arguments in support of their position will be either question-begging or self-contradictory. To argue in favour of the normative status of logic involves the assumption that the issue is substantive. I draw a distinction between deontic and axiological normativity as applied to logical theory and demonstrate that because deontic sentences are not truth-functional, logic cannot be normative in the deontic sense. I conclude that the only sense in which logical theory may be thought of as normative is axiologically.

Key WORDS: logic, logical normativity, normative logic, logical theory, deontology, axiologic 